Institute of $\mathbf{F}_{\text {ood and }} \mathbf{A}_{\text {gricultural }} \mathbf{S}_{\text {ciences }}$

\title{
Housing As We Grow Older: Design Considerations for a Supportive Environment ${ }^{1}$
}

Virginia Peart and Carolyn Wilken ${ }^{2}$

\section{Our Living Environment}

We don't often stop to think about our immediate living environment -- our house or apartment -- and the impact it has upon our lives. Some of us live in relatively comfortable, supportive environments and take them for granted. It is only when we have specific problems -- like a broken light switch or not enough space for a houseful of guests -- that we really take a close look at our living space.

It is important to recognize that our living space may not always meet our needs as well as it does now. As we grow older, our needs may change. What are now minor annoyances may become major problems. A flight of stairs may be more difficult to climb. An extra room may become difficult to heat and maintain.
We may continue to live in our own homes -- as the vast majority of older Americans currently do. However, it is important to take a closer look at both our living space and our needs and abilities. We must be sure that our homes will continue to meet our needs in years to come.

\section{Our Environmental Needs}

In thinking about our living environment, it is often helpful to think about how our home can help us fulfill our needs and desires. On the one hand, our environment should safe, convenient and without barriers.

Equally important, and perhaps less often considered, our living space can enrich our lives as well. It may provide space for a garden, a bit of extra space for a hobby, or a porch where we can talk to our neighbors.

1. This document is Fact Sheet FCS 3189, a series of the Department of Family, Youth and Community Sciences, Florida Cooperative Extension Service, Institute of Food and Agricultural Sciences, University of Florida. Publication date: November 2002. First published: January 1994. Revised: November 2002. Please visit the EDIS web site at http://edis.ifas.ufl.edu

2. Written by Virginia Peart, former associate professor, Housing; revised by Carolyn Wilken, associate professor, Family Life; and reviewed by Nayda I. Torres, professor, Family and Consumer Economics, Department of Family, Youth and Community Sciences, Cooperative Extension Service, Institute of Food and Agricultural Sciences, University of Florida, Gainesville, 32611. 
These things may become more important as we grow older. Outside activities may be reduced and more time may be spent at home.

Each of us has somewhat different environmental needs at every age. There are five broadly defined needs which almost all of us share to some degree. Our living environment can help to satisfy these needs.

1. Safety and security. It is important to be able to see a visitor at the front door and to know that there are no potentially slippery surfaces in bathrooms or kitchens.

2. Comfort and clarity. As we get older, we may become less agile and more sensitive to extremes of temperature. Changes in vision and hearing may make it more difficult to take in information from our surroundings. It is important to eliminate unnecessary stretching to top or bottom shelves, to provide better lighting, and to ensure that controls such as oven dials and thermostats are large and can be read clearly.

3. Privacy and control. Many of us have lived all of our lives in places where we have been free to change our environment as we please. We have been able to choose how much privacy we want, temperature and noise levels, and other important aspects of our living environment. This control doesn't just happen, it must be planned.

4. Social contact. In our living environment we need spaces where we can meet and entertain others when we choose. Elevator lobbies, front porches, and backyard fences are all familiar examples of places we meet and talk with others.

\section{Independence and personal}

development. We all want to be able to do things for ourselves, for the challenge and stimulation as well as for support and convenience. Part of maintaining our competence as individuals is the ability to continue to pursue current interests and to develop new ones.

It is important to recognize that these five needs are closely interrelated. Feeling safe and secure at home is influenced by our feeling of control over our living environment. The knowledge that there are neighbors nearby to call upon if needed is comforting. Likewise, privacy is most satisfying when we also have regular social contact with other people.

\section{Assessing Our Environment}

We can evaluate our environment from the city or region down to a single room in our home. Our primary focus, however, will be on our home and our neighborhood/ community.

\section{Neighborhood/Community}

The neighborhood is an important part of our living environment. Does the neighborhood provide a variety of services? Can they be reached on foot or is a car required?

Is there adequate street lighting? Are there enough people around to discourage criminal activity? Are there other people with similar interests? All of these factors 
clearly influence the support available any living environment

\section{The Total House}

Size, level of maintenance, accessibility, and amenities all affect the degree of support a home provides.

Size and Layout. Older persons often live in older, larger homes. Thus, it is important to think about how much space will be needed as family size changes over time. More space means more area to heat in the winter, cool in summer, and maintain year round. At the same time, less space might limit entertaining or other interests.

The orientation -- the direction the house faces -- is important for energy savings. For example, most of the windows should face south to take advantage of warmth from the sun for heat.

The layout is important for mobility. An injury, even a temporary one, can change a flight of stairs into a barrier. Does your home have a sleeping area and a bathroom on the first floor? Do you have a straight flight of stairs where you could install a stair lift?

It is possible to remodel your home to create a self-contained living unit on the first floor and a separate rental apartment upstairs? That would reduce the amount of space which must be maintained, and could represent a useful source of income and social contact. Local zoning ordinances, along with house layout, will determine whether such an approach is possible.

Maintenance. The amount of home maintenance needed affects safety, security, comfort, and economy. Ask your local fire department to inspect your home for fire hazards. They also can provide advice on smoke alarms, fire extinguishers, and escape ladders. Check windows and doors to be sure they are secure. If the front door has a "peephole," check to make sure that it's at the proper height.

Older, larger homes often have less insulation and are more expensive to heat and cool. They also may be less comfortable for older persons who are more sensitive to temperature extremes. Ask your local utility company to evaluate your home energy use and suggest ways to increase fuel efficiency.

Accessibility. The whole house should be as accessible as possible to both residents and guests. Avoid sharply sloping paths and flights of stairs. Is it possible to build a level entry or a ramp into the house with a maximum slope of one foot for every twelve feet of length?

The recent interest in "barrier-free" environments has created excellent resources for making homes more accessible for people who need to use a cane or walker, or are in wheelchairs. Much of this information may be available through local organizations, such as the Easter Seal Society. A quick, effective way to learn about barriers and accessibility is to enter and move through your home using a mobility aid.

\section{Living Space}

Living rooms, studys, dens, and parlors ought to provide adequate space for entertaining friends, hobbies, and for the display of valued furniture, accessories, and photos. Is it possible to see out of the 
windows while seated in a chair (the bottom sill of the window should be no higher than 2 feet 6 inches)? Is the TV away from the glare of windows? Is there space for a stool, chair, or bench near the front door for putting on and removing boots and winter clothing? Is there some degree of privacy between living and cooking areas?

\section{Kitchen and Eating Areas}

Kitchens and dining areas are often the center of family life. They should be safe and pleasant places for family members and visitors.

Safety is important in food preparation areas. Are oven controls clearly marked (color coding helps) and easy to grasp? Are they located at the front of the oven or on the side so it is not necessary to reach over hot burners? Is there an area adjacent to the oven for quickly setting down hot and/or heavy pots and pans?

Are sink faucets clearly marked and easy to operate? "Single stick" controls seem to function particularly well. Do you have a high faucet or spray so you can fill large bowls and pots on adjacent work counters without lifting them into and out of the sink?

Is it possible to prepare meals while sitting? This can reduce fatigue and is obviously necessary for anyone in a wheelchair. Slide-out boards under counter tops can help the seated worker.

Organize food and storage areas to eliminate uncomfortable bending. Be sure to keep door and drawer handles below eighteen inches. Avoid dangerous reaching to top shelves while balanced on chairs or stools.
A kitchen serving cart can be very useful for storage and moving large and heavy pots and pans. Adequate counter space near the range and refrigerator is needed, as well as counter space for food preparation.

Is the flooring in food preparation areas made of a safe and non-slip material? Is there adequate lighting for kitchen tasks? Could supplemental lighting be added under wall cabinets?

Finally, consider whether a person in a wheelchair could operate effectively in the kitchen. Are there adequate clearances? Can under-sink panels be removed to allow a person to wheel under it? Are under-sink pipes adequately insulated to prevent burns?

\section{Sleeping Areas}

While most of us spend limited time in our bedrooms, illness or injury could potentially reduce our total living environment to this space. Is there enough space for a TV, hobbies, or for visitors? Is it possible to look out of a window from the bed? Is there a jack for a telephone?

Is there direct and safe access from bedroom to bathroom? Is there adequate clearance of forty inches at the foot or side of the bed for making it, and twenty inches at other side(s)?

\section{Bathroom}

Are tub and sink fixtures clearly marked and easy to operate? Do you have a bath or half bath on each level of living space? Do tubs and/or showers have non-slip surfaces? 
Is it possible to install secure grab bars adjacent to tub and toilet? Is it possible to place a seat in the shower and install a hand-held shower head so that it is not necessary to stand? Are hot water pipes adequately insulated to prevent burns?

Is it possible to install a phone or a call button for potential emergencies? Does the bathroom door open out to make sure that it can be opened in an emergency?

A final note, a traditional shower curtain is safer than a glass shower enclosure. A shower curtain makes it easier to get into and out of the shower.

\section{Circulation Spaces}

For safety and security, are halls are well lit, wide (minimum 3 feet 4 inches), and free of potential hazards? Are stairs well lit? Do they have secure hand rails on both sides?

Is it possible to see the leading edge of each stair tread while walking down? Are there any throw rugs on which one could accidentally slip? Are there thresholds into rooms with one or two step changes in level that could be dangerous if not noticed?

\section{Other Furnishings and Equipment}

As one grows older, lighting required for particular tasks increases. It is important to provide glare-free light. Shades, draperies, curtains, or awnings can all minimize glare problems from exterior light. Non-reflective surfaces and eliminating sharp light/dark contrasts can minimize glare from interior sources.
It is best to have wall switches immediately next to doorways to avoid entering a darkened space to turn on lights. Since furniture in a room may be used occasionally for support while walking, it should be sturdy and stable enough for support.

Can windows be opened easily? In general, casement and sliding windows are easier to operate than double-hung ones. Are window sills wide enough to hold plants for indoor gardening?

Are exterior and interior door handles and locks easy to operate? Lever action door handles are usually better than round ones, particularly those round smooth knobs that are difficult to grip

\section{Alternative Sources of Support}

Our physical environment and our social environment are equally important. To extend our ability to live independently and productively in our homes, we need a variety of services including nutrition programs, handyman and homemaker services, and regular visitors.

\section{Design Considerations for a Supportive Environment: Checklist}

Answering the following questions should give you a better idea of how well present or potential living environments may meet your needs both now and in years to come.

\section{The Neighborhood/Community}

- Does the neighborhood provide services, such as shopping, recreation, transportation, medical care? 
- Are residents of the neighborhood people with whom you have, or could develop, common interests and friendships?

- Is the neighborhood safe and secure?

\section{The Home}

- Is the home a reasonable size, in good repair, and economical to maintain?

- Is it possible to live on the first floor of the home if necessary?

- Does house design and local zoning allow for possible subdivision and rental?

- Is the home accessible and barrier-free both inside and from the street?

\section{Living Spaces}

- Are living room, den, and study of adequate size for entertaining friends, pursuing hobbies, and arranging favorite furnishings and mementos?

- Do windows provide a view, particularly when you are seated?

- Can you easily keep an eye on the entry, yard, and sidewalk?

\section{Kitchen and Eating Areas}

- Are sink and oven controls clearly marked and easy to operate?

- Is it possible to sit while preparing food to minimize fatigue and/or accommodate a wheelchair?
- Is there enough storage for food and cooking utensils? Are storage spaces easy to reach?

- Is there enough light in the kitchen, particularly on work surfaces?

- Is the kitchen floor made of non-skid material?

\section{Sleeping Areas}

- Is there enough bedroom space for moving about, dressing, TV, hobbies, or visitors?

- Is there convenient and safe access to a bathroom?

- Is it possible to look out of a window while sitting or lying in bed?

\section{Bathroom}

- Is it possible to mount grab bars securely next to toilet and tub?

- Is it possible to put a stool in the shower and to install a hand-held shower head?

- Are sink, tub, and shower controls clearly marked and easy to operate?

- Are flooring and tub bottom of non-slip materials?

- Is there storage space for linens and medical supplies in or near the bathroom?

\section{Circulation Spaces}

- Are halls and stairs well lit and free of obstructions (throw rugs, thresholds, changes in level)? 
- Do stairs and, if desired, hallways have sturdy and well-fastened hand rails?

\section{Furnishings and Fixtures}

- Is there enough lighting in each room?

- Can lights be turned on by wall switches next to doorways?
- Are furnishings sturdy enough and properly located to provide support while standing or walking?

- Are shades, blinds, or draperies used to minimize glare through windows?

- Are carpeting and rugs low-pile or no-pile type to avoid tripping? 